\title{
Comparison of Two Sampling Procedures for Diagnosing Endometrial Carcinoma and Hyperplasia: Outpatient Tissue Biopsy Versus Cytologic Examination
}

\author{
Makoto Motegi ${ }^{1}$, Shiro Tanaka ${ }^{2}$, Harue Tada ${ }^{2}$, Toru Sasaki ${ }^{3}$, Akihiko Hashi ${ }^{4}$, Hirokuni Takano ${ }^{1}$ and Hiroshi Sasaki ${ }^{1 *}$ \\ ${ }^{1}$ Department of Obstetrics and Gynecology, Jikei Kashiwa Hospital, 163-1Kashiwashita, Kashiwa-shi, Chiba277-8567, Japan \\ ${ }^{2}$ Department of Clinical Trial, Design \& Management, Translational Research Center, Kyoto University Hospital, 54 Shogoin Kawahara-Cho, Sakyo-ku, Kyoto 606-8507, \\ Japan \\ ${ }^{3}$ Department of Obstetrics and Gynecology, Tokyo Medical University, 6-7-1 NishiShinjuku, Shinjuku-ku, Tokyo 160-0023, Japan \\ ${ }^{4}$ Department of Obstetrics and Gynecology, National University Corporation University of Yamanashi, 1110 Shimokato Chuo-shi, Yamanashi 409-3898, Japan
}

\begin{abstract}
Background: We compared the sensitivity of 2 diagnostic procedures—-tissue biopsy and cytologic examinationfor detecting endometrial carcinoma and hyperplasia in outpatients. The patients' degree of acceptance of these methods was also evaluated.

Methods: The study included 124 women who had been diagnosed with carcinoma and hyperplasia by histological examination in private clinics or were suspected to have endometrial carcinoma and hyperplasia-for example, those presenting with uterine bleeding and/or abnormal endometrial morphology on cytologic examination—at Jikei University Hospital, University of Yamanashi Hospital and National Hospital Organization Kure Medical Center from January 28, 1999, to August 28, 2006. Both cytologic examination (using Endocyte ${ }^{\circledR}$ ) and tissue biopsy (using Suresample ${ }^{\mathrm{TM}}$ ) of the endometrium were performed before complete curettage and/or hysterectomy. The diagnosis made using these two outpatient procedures was compared to the final diagnosis made using curettage and/or hysterectomy. McNemar's chi-square test was used to evaluate the statistical significance.
\end{abstract}

Results: The sensitivity of tissue biopsy for detecting endometrial carcinoma and hyperplasia was $84 \%$ and $91 \%$, respectively, and that of cytologic examination was $78 \%$ and $55 \%$, respectively. There was a significant difference in the sensitivity of the 2 methods for detecting hyperplasia $(p=0.045)$. No patients complained of severe pain, and no other complication occurred during both methods. Both methods were well tolerated by the patients.

Conclusion: Our data indicate a certain diagnostic superiority of tissue biopsy over cytologic examination.

Keywords: Endocyte ${ }^{\circledR}$; Suresample ${ }^{\mathrm{TM}} ;$ Endometrial carcinoma; Hyperplasia; Diagnostic procedure

\section{Introduction}

Each year, there are about 142,000 new cases of endometrial carcinoma worldwide, and an estimated 42,000 women die because of this type of cancer [1]. The surgical stage, determined according to the criteria of the International Federation of Gynecology and Obstetrics, reflects the 5 -year survival, which is around $85 \%$ for stage I, $75 \%$ for stage II, $45 \%$ for stage III, and $25 \%$ for stage IV disease [1]. Endometrial cancer is often preceded by endometrial hyperplasia, which is a spectrum of morphologic and biologic alterations of the endometrial glands and stroma and is often secondary to hyperestrogenism. It has been shown that progression to carcinoma occurs in $1 \%$ of patients with simple hyperplasia, $3 \%$ of patients with complex hyperplasia, $8 \%$ of patients with simple hyperplasia with atypia, and $29 \%$ of patients with complex hyperplasia with atypia [2].

The Japanese Ministry of Health and Welfare investigated the effectiveness of mass endometrial carcinoma screening. During the 9 -year study, 126 cases were detected by mass screening and 1,069 cases were diagnosed in outpatient clinics. Early-stage cases were significantly more frequent in the screening group ( $\mathrm{p}<0.001): 88.1 \%$ of the patients in the screening group had stage I disease, as compared to $65.3 \%$ of the patients in the outpatient group. The 5-year survival rate was also significantly higher in the screening group than in the outpatient group ( $94.7 \%$ vs $84.3 \% ; p=0.041)$ [3]. These statistics suggest that early detection of endometrial carcinoma and hyperplasia is necessary to improve the prognosis of these diseases.
Outpatient endometrial sampling is now replacing complete curettage as the method of choice for diagnosing endometrial disease. This procedure is easy to perform, associated with minimal patient discomfort, and reported to be highly sensitive in detecting endometrial carcinoma [4-14]. The Pipelle de Cornier ${ }^{\circledR}$ device (Laboratoire CCD, Paris, France) is an endometrial biopsy sampler that is seemingly better tolerated by patients than most other endometrial biopsy devices $[15,16]$. However, we cannot use this device because it is not available in Japan. Instead, we collect endometrial tissue by using the Suresample ${ }^{\mathrm{TM}}$ (Smith Medical International Ltd., Kent, UK) endometrial sampler, which is similar to the Pipelle ${ }^{\circledR}$ device. This endometrial sampler has an aperture not only on the side near the distal tip, similar to the Pipelle ${ }^{\mathbb{R}}$ device, but also at the distal tip and is expected to collect a larger sample. However, in Japan, cytologic examination is often used initially to detect endometrial carcinoma and its precursor stages, as stipulated by a 1987 health insurance law for the elderly. During this cytologic

*Corresponding author: Hiroshi Sasaki M.D., Ph.D, 163-1 Kashiwashita, Kashiwa-shi, Chiba 277-8567, Japan, Tel: +81-4-7164-1111; Fax: +81-4-71669374; E-mail: hrssasaki@jikei.ac.jp

Received March 25, 2011; Accepted May 17, 2011; Published May 19, 2011

Citation: Motegi M, Tanaka S, Tada H, Sasaki T, Hashi A, et al. (2011) Comparison of Two Sampling Procedures for Diagnosing Endometrial Carcinoma and Hyperplasia: Outpatient Tissue Biopsy Versus Cytologic Examination. J Cyto Histol 2:118. doi:10.4172/2157-7099.1000118

Copyright: (C) 2011 Motegi M, et al. This is an open-access article distributed under the terms of the Creative Commons Attribution License, which permits unrestricted use, distribution, and reproduction in any medium, provided the original author and source are credited. 
examination, endometrial cells are collected using the Endocyte ${ }^{\mathbb{R}}$ sampler (Laboratoire CCD, Paris, France). The cell processing technique is similar to that used for a cervical cytology smear and is thus relatively inexpensive.

A few studies have compared the 2 above-mentioned sampling procedures. However, in these studies, the diagnostic sensitivity was not sufficiently evaluated because of the small number of carcinoma and hyperplasia cases used for the investigation $[13,17]$. In the present study, in order to determine the optimal technique for detection of endometrial carcinoma and hyperplasia, we compared the diagnostic sensitivity of cytologic examination using Endocyte ${ }^{\circledR}$ and tissue biopsy using Suresample ${ }^{\mathrm{TM}}$; we also estimated the degree of patient acceptance for both these procedures.

\section{Materials and Methods}

This study included 124 patients who had been diagnosed with carcinoma and hyperplasia by histological examination in private clinics or were suspected of having carcinoma and hyperplasia-for example, those presenting with uterine bleeding and/or abnormal endometrial morphology on cytologic examination-at Jikei University Hospital, University of Yamanashi Hospital and National Hospital Organization Kure Medical Center from January 28, 1999, to August 28, 2006. Patients with complications such as pregnancy, acute pelvic infection, infection of the uterine cervix, and coagulation disorder were excluded. Both cytologic examination and tissue biopsy were performed for all the patients; the former was performed before the latter. This study was approved by the hospital ethics committees, and informed consent was obtained from all the patients.

Cytologic materials were obtained using Endocyte ${ }^{\circledR}$. The Endocyte ${ }^{\circledR}$ sampler is composed of flexible plastic, is presterilized, and measures 21 $\mathrm{cm}$ in length; its greatest external diameter is $2.6 \mathrm{~mm}$. Along its length are graduation marks that guide the operator in introducing the device into the endometrial cavity, as described by Byrne [8]. The collected cellular components were placed on a glass slide, crushed, and smeared using the regular pull-apart method. After fixation in $95 \%$ alcohol, Papanicolaou staining was performed. The cytologic findings were divided into different classes on the basis of structural abnormalities, such as papillary clusters, type A stroma, arborescent clusters, and back-to-back structures (Table 1) $[18,19]$. Outpatient tissue biopsy was performed using Suresample ${ }^{\mathrm{TM}}$. Suresample ${ }^{\mathrm{TM}}$ is a flexible, clear polypropylene suction curette containing an internal piston and measures $24 \mathrm{~cm}$ in length and $3.1 \mathrm{~mm}$ in external diameter. It has a round aperture with a diameter of $1.5 \mathrm{~mm}$ at the distal tip of its sheath and 2 oval apertures each measuring $5.9 \times 1.5 \mathrm{~mm}$ at $3.2 \mathrm{~mm}$ from the distal tip. In order to obtain a specimen, the device is inserted into the uterine cavity and negative pressure is then created within the sheath by withdrawing the piston. The device is rotated while also being moved back and forth several times within the uterine cavity. Suresample ${ }^{\mathrm{TM}}$ is then withdrawn, and the tissue sample is ejected into $10 \%$ buffered formalin by using the piston. The entire sample is histologically examined.

After collecting the sample for both procedures, the patient was asked to comment on the intensity of any pain experienced during the procedure. Pain or discomfort was subjectively graded as mild, moderate, or severe. Thereafter, in 93 patients, complete curettage and/ or hysterectomy was performed. In the remaining 31 patients, these procedures were not performed because of the attending physician's decision or the patient's refusal. The final diagnosis was made on the basis of the histological findings of the samples obtained during complete curettage and/or hysterectomy. The diagnosis made using both outpatient procedures was then compared with the final diagnosis.

We estimated sensitivity for detecting endometrial carcinoma, sensitivity for detecting endometrial hyperplasia, and specificity of each procedure separately and reported them with $95 \%$ confidence intervals. Patients who were not diagnosed histologically were excluded from this analysis. McNemar's chi-square test was used to compare each measure of diagnostic accuracy. All reported $p$ values for statistical tests are twotailed, and $p<0.05$ was taken to indicate statistical significance. Data management and statistical analysis were conducted at an independent academic data center, Translational Research Center, Kyoto University Hospital, using SAS version 9.2 (SAS Institute, Cary, NC).

\section{Results}

The median age of the patients was 54 years (range: $23-85$ years). Of the 124 patients, 68 (55\%) were postmenopausal, and 88 (71\%) showed abnormal uterine bleeding.

Of the 93 patients who underwent complete curettage and/or hysterectomy, 69 were finally diagnosed with endometrial carcinoma, 11 with endometrial hyperplasia, 6 with other tumor, and 7 with normal endometrium. Of the 69 patients with endometrial carcinoma, 50 had endometrioid adenocarcinoma; 12 , adenoacanthoma; 2 , serous papillary adenocarcinoma; 2 , clear cell adenocarcinoma; 1 , mucinous adenocarcinoma; and 2, mixed carcinoma. Of the 50 endometrioid adenocarcinoma tumors, 33 were well differentiated, 12 were moderately differentiated, and 5 were poorly differentiated. Of the 11 patients with endometrial hyperplasia, 5 had complex hyperplasia with atypia, 3 had complex hyperplasia without atypia, and 3 had simple hyperplasia without atypia.

Of the 69 patients with endometrial carcinoma, cytological examination using Endocyte ${ }^{\circledR}$ revealed carcinoma (class V) in 54 patients, hyperplasia (class III or IV) in 7, and a normal endometrium (class II) in 5 ; in 3 patients, adequate samples could not be obtained.

\begin{tabular}{|l|l|}
\hline Class & Findings \\
\hline I & No abnormal findings. \\
\hline II & $\begin{array}{l}\text { Inflammatory findings or reactive changes because of an intrauterine } \\
\text { device(IUD). }\end{array}$ \\
\hline IIb & $\begin{array}{l}\text { Papillary clusters with few structural abnormalities. } \\
\text { Complex hyperplasia not fully suspected but follow-up necessary. }\end{array}$ \\
\hline III & $\begin{array}{l}\text { Papillary clusters accompanied by structural abnormalities. } \\
\text { Complex hyperplasia suspected. }\end{array}$ \\
\hline IV & $\begin{array}{l}\text { Small number of arborescent clusters. } \\
\text { Complex hyperplasia with atypia or worse suspected. }\end{array}$ \\
\hline V & $\begin{array}{l}\text { Clear glandular cavity with back-to-back structures and arborescent } \\
\text { clusters. Endometrial cancer diagnosed. }\end{array}$ \\
\hline
\end{tabular}

Table 1: Different classes of cytologic findings of the endometrium.

\begin{tabular}{|l|l|l|l|l|l|l|}
\hline \multicolumn{7}{|l|}{ Final histological diagnosis } \\
\hline $\begin{array}{l}\text { Cytology } \\
\text { (class) }\end{array}$ & $\begin{array}{l}\text { Normal } \\
\text { endometrium }\end{array}$ & EH (Atypical) & EMCA & $\begin{array}{l}\text { Other } \\
\text { tumor }\end{array}$ & $\begin{array}{l}\text { Not } \\
\text { performed }\end{array}$ & Total \\
\hline I & 3 & 0 & 0 & 0 & 6 & 9 \\
\hline II & 4 & $5(1)$ & 5 & 1 & 13 & 28 \\
\hline III & 0 & $5(3)$ & 6 & 1 & 4 & 16 \\
\hline IV & 0 & $1(1)$ & 1 & 0 & 3 & 5 \\
\hline V & 0 & 0 & 54 & 4 & 2 & 60 \\
\hline Inadequate & 0 & 0 & 3 & 0 & 3 & 6 \\
\hline Total & 7 & $11(5)$ & 69 & 6 & 31 & 124 \\
\hline
\end{tabular}

EH: endometrial hyperplasia; EMCA: endometrial carcinoma

Table 2: Comparison between cytologic examination and the final histological study. 


\begin{tabular}{|l|l|l|l|l|l|l|}
\hline \multicolumn{7}{|l|}{ Final histological diagnosis } \\
\hline Biopsy & $\begin{array}{l}\text { Normal } \\
\text { endometrium }\end{array}$ & $\begin{array}{l}\text { EH } \\
\text { (Atypical) }\end{array}$ & EMCA & $\begin{array}{l}\text { Other } \\
\text { tumor }\end{array}$ & $\begin{array}{l}\text { Not } \\
\text { performed }\end{array}$ & Total \\
\hline $\begin{array}{l}\text { Normal } \\
\text { endometrium }\end{array}$ & 6 & 0 & 0 & 3 & 17 & 26 \\
\hline EH & 1 & $10(5)$ & 6 & 0 & 4 & 21 \\
\hline EMCA & 0 & 0 & 58 & 1 & 1 & 60 \\
\hline Other tumor & 0 & 0 & 0 & 1 & 2 & 3 \\
\hline Inadequate & 0 & 1 & 5 & 1 & 7 & 14 \\
\hline Total & 7 & $11(5)$ & 69 & 6 & 31 & 124 \\
\hline
\end{tabular}

EH: endometrial hyperplasia; EMCA: endometrial carcinoma

Table 3: Comparison between outpatient biopsy and the final histological study.

\begin{tabular}{|l|l|l|l|l|l|}
\hline & \multicolumn{2}{|l|}{$\begin{array}{l}\text { Cytologic examination } \\
\text { (95\% Confidence interval) } \\
(\%)\end{array}$} & $\begin{array}{l}\text { Tissue biopsy } \\
(95 \% \text { Confidence } \\
\text { interval) }(\%)\end{array}$ & $\mathrm{p}^{* 1}$ \\
\hline $\begin{array}{l}\text { Sensitivity for detecting } \\
\text { endometrial carcinoma }\end{array}$ & 78.3 & $(66.7-87.3)$ & 84.1 & $(73.3-91.8)$ & 0.157 \\
\hline $\begin{array}{l}\text { Sensitivity for detecting } \\
\text { endometrial hyperplasia }\end{array}$ & 54.5 & $(23.4-83.3)$ & 90.9 & $(58.7-99.8)$ & 0.045 \\
\hline Specificity & 100.0 & $(59.0-100.0)$ & 85.7 & $(42.1-99.6)$ & $* 2$ \\
\hline
\end{tabular}

${ }^{* 1}$ McNemar's chi-square test

${ }^{*}$ Not calculable due to specificity of $100 \%$

Table 4: Comparison of diagnostic accuracy between cytologic examination and tissue biopsy.

Tissue biopsy using Suresample ${ }^{\mathrm{TM}}$ identified 58 cases of endometrial carcinoma, while 6 were misdiagnosed as endometrial hyperplasia. In 5 patients, adequate samples could not be obtained. Of the 11 patients with endometrial hyperplasia, cytologic examination using Endocyte ${ }^{\circledR}$ revealed hyperplasia (class III or IV) in 6 patients and a normal endometrium (class II) in 5. Tissue biopsy using Suresample ${ }^{\mathrm{TM}}$ helped to identify 10 cases of hyperplasia; in 1 patient, an adequate sample could not be obtained (Table 2 and Table 3). The sensitivity of Endocyte ${ }^{\circledR}$ and Suresample ${ }^{\mathrm{TM}}$ for detecting endometrial carcinoma was $78 \%$ and $84 \%$, whereas the sensitivity for detecting endometrial hyperplasia was $55 \%$ and $91 \%$, respectively. The specificity of Endocyte ${ }^{\circledR}$ and Suresample ${ }^{\mathrm{TM}}$ for detecting endometrial disease was $100 \%$ and $86 \%$, respectively. These data suggest that as compared to cytologic examination using Endocyte $^{\circledR}$, outpatient endometrial tissue biopsy using Suresample ${ }^{\mathrm{TM}}$ has a significantly higher sensitivity for detecting endometrial hyperplasia $(\mathrm{p}=0.045 ;$ Table 4$)$.

Pain was reported to be nil by 42 (34\%) and 49 (40\%) patients, mild by $69(56 \%)$ and $67(54 \%)$ patients, and moderate by $13(10 \%)$ and 8 (6\%) patients during the insertion of Endocyte ${ }^{\circledR}$ and Suresample ${ }^{\mathrm{TM}}$, respectively. None of the patients complained of severe pain. Pain was reported to be nil by $30(24 \%)$ and $42(34 \%)$ patients, mild by $77(62 \%)$ and $70(56 \%)$ patients, and moderate by $17(14 \%)$ and $12(10 \%)$ patients during the collection of samples using Endocyte ${ }^{\circledR}$ and Suresample ${ }^{\mathrm{TM}}$, respectively. No patient complained of severe pain. In all patients, bloody discharge from the cervix after cell collection was either absent or minimal.

\section{Discussion}

To the best of our knowledge, this is the first study to investigate the diagnostic accuracy of outpatient endometrial tissue biopsy using Suresample ${ }^{\mathrm{TM}}$. However, there are several studies on the use of the Pipelle $^{\circledR}$ device, which is similar to Suresample ${ }^{\mathrm{TM}}[4-7,13,15,16]$. A meta-analysis revealed that the Pipelle ${ }^{\circledR}$ device has a sensitivity of $99.6 \%$ and $91 \%$ in postmenopausal and premenopausal patients, respectively [5]. Another review showed that the sensitivity of the Pipelle ${ }^{\circledR}$ device varies between $86 \%$ and $100 \%$ [4]. We found the sensitivity of
Suresample ${ }^{\mathrm{TM}}$ to be $84 \%$, which is lower than that of the Pipelle ${ }^{\circledR}$ device, as mentioned above. In the present study, the inadequate sample (no specimen obtained or insufficient specimen for adequate assessment for histological or cytological diagnosis) at the outpatient examination was regarded as 'negative' for the calculation of the sensitivity, in contrast to some previous studies where inadequate diagnoses were excluded from the calculations $[4,8,10-12]$. Had we calculated sensitivity by excluding inadequate samples, the sensitivity of Suresample ${ }^{\mathrm{TM}}$ for detecting endometrial carcinoma would be $91 \%$, which is similar to the values reported in previous studies. Moreover, no patient with carcinoma was falsely diagnosed as having a normal endometrium by outpatient tissue biopsy. Other reports have showed that the sensitivity of cytologic examination for diagnosing endometrial carcinoma is $74.1-100 \%$ [814]. One study evaluated and compared the accuracy of sampling using Endopap $^{\circledR}$ and Pipelle ${ }^{\circledR}$ for diagnosing postmenopausal disease. The sensitivity of Endopap ${ }^{\circledR}$ and Pipelle ${ }^{\circledR}$ for detecting endometrial disease was $56 \%$ and $51 \%$ and the specificity was $94 \%$ and $100 \%$, respectively. The sensitivity for endometrial carcinoma was $80 \%$ for Endopap ${ }^{\circledR}$ and $100 \%$ for Pipelle ${ }^{\circledR}$. The authors therefore favored Pipelle ${ }^{\circledR}$ for diagnosing endometrial disease in symptomatic postmenopausal women [13]. In the present study too, the sensitivity of cytologic examination for detecting carcinoma tended to be lower than that of outpatient tissue biopsy. Furthermore, 5 patients with carcinoma were falsely diagnosed as having a normal endometrium by cytologic examination. Such false negatives pose a grave risk for patients when screened for endometrial carcinoma.

Outpatient endometrial sampling also aims to detect endometrial hyperplasia, because of the supposed role of the latter as a precursor of endometrial carcinoma. However, detecting endometrial hyperplasia in the smears of endometrial samples is very difficult. Therefore, the diagnostic rate is not always high because of the lack of cellular atypia. In fact, it has been reported that hyperplasia can be detected in only $32.3-80.5 \%$ of cases $[8-12,14]$. A meta-analysis shows that the sensitivity of the Pipelle ${ }^{\circledR}$ device in detecting atypical hyperplasia is $81 \%$ [5]. In the present study, the sensitivity of cytologic examination for detecting hyperplasia was 55\%, whereas that of outpatient tissue biopsy was $91 \%$. Thus, the difference between the sensitivity of these 2 methods is significant ( $\mathrm{p}=0.045)$.

At the time of sampling, adverse effects such as severe pain and bloody discharge decrease the patient's acceptance of the collection method. The adverse effects of the Pipelle ${ }^{\circledR}$ device, used without anesthesia, have been evaluated by surveying 40 patients. Although 2 patients (5\%) complained of severe pain, none of the biopsy attempts were prematurely terminated as a result of pain and no complications related to endometrial sampling occurred [6]. The incidence and intensity of pain during and after a cytologic procedure using Endocyte ${ }^{\circledR}$ have also been examined. The present pain intensity index developed by Melzack assesses the overall discomfort or pain experienced on a scale of $0-5$. Pain was reported as 0 (no pain) by $60 \%$ patients, as 1 (mild) by $30 \%$, and as 2 (discomfort) by $10 \%$ [17,20]. In the present study, the intensity of pain tend to be stronger during cytologic examination using Endocyte ${ }^{\circledR}$ than tissue biopsy using Suresample ${ }^{\mathrm{TM}}$, despite the larger diameter of the Suresample ${ }^{\mathrm{TM}}$ probe. As the cytologic examination performed before the tissue biopsy made the insertion of the Suresample ${ }^{\mathrm{TM}}$ probe easier, we cannot provide definitive conclusions on the superiority of Suresample ${ }^{\mathrm{TM}}$ with regard to patient acceptance. However, during both procedures, none of the patients complained of severe pain and no complications occurred. This suggests that both outpatient sampling procedures were well tolerated, which is a finding consistent with those of previous reports $[6,17,20]$. 
Citation: Motegi M, Tanaka S, Tada H, Sasaki T, Hashi A, et al. (2011) Comparison of Two Sampling Procedures for Diagnosing Endometrial Carcinoma and Hyperplasia: Outpatient Tissue Biopsy Versus Cytologic Examination. J Cytol Histol 2:118. doi:10.4172/2157-7099.1000118

Our data indicated a certain diagnostic superiority of outpatient tissue biopsy to cytologic examination. Because of the small number of patients with a normal endometrium, we could not sufficiently evaluate the specificity for detecting endometrial disease. Furthermore, this study did not compare the two methods in terms of cost effectiveness. Therefore, cytologic examination for detecting endometrial carcinoma and hyperplasia cannot be completely disregarded. Yet, our data suggest that the use of tissue biopsy in an endometrial carcinoma screening program might improve the detection rate of endometrial carcinoma and hyperplasia. For example, in the cases of patients with normal endometrial morphology on cytologic examination, who show strongly suspicious symptoms such as abnormal endometrium thickness on the ultrasonography and/or continuous genital bleeding, reexamination using tissue biopsy should be considered. Diagnostic superiority of outpatient tissue biopsy to cytologic examination is most likely because cytologic examination cannot provide the architectural detail. Recently, liquid-based cytology and cell block preparation were reported as the methods that had more excellent architectural preservation than conventional cytologic examination. Several reports suggest that those methods are useful for diagnosing endometrial disease [21-23]. Further studies focusing on the effectiveness of various methods including liquid-based cytology and cell block preparation are necessary.

\section{Acknowledgements}

The authors acknowledge Dr. Tsuneo Fujii for his contribution to data collection. We thank all the participating patients for their enthusiastic collaboration, without this work would not have been possible.

\section{References}

1. Amant F, Moerman P, Neven P, Timmerman D, Van Limbergen E, et al. (2005) Endometrial cancer. Lancet 366: 491-505.

2. Kurman RJ, Kaminski PF, Norris HJ (1985) The behavior of endometrial hyperplasia. A long-term study of "untreated" hyperplasia in 170 patients. Cancer 56: 403-412.

3. Nakagawa-Okamura C, Sato S, Tsuji I, Kuramoto H, Tsubono Y, et al. (2002) Effectiveness of mass screening for endometrial cancer. Acta Cytol 46: 277283.

4. Clark TJ, Mann CH, Shah N, Khan KS, Song F, et al. (2002) Accuracy of outpatient endometrial biopsy in the diagnosis of endometrial cancer: a systematic quantitative review. BJOG 109: 313-321.

5. Dijkhuizen FP, Mol BW, Brölmann HA, Heintz AP (2000) The accuracy of endometrial sampling in the diagnosis of patients with endometrial carcinoma and hyperplasia: a meta-analysis. Cancer 89: 1765-1772.

6. Stovall TG, Photopulos GJ, Poston WM, Ling FW, Sandles LG (1991) Pipelle endometrial sampling in patients with known endometrial carcinoma. Obstet Gynecol 77: 954-956.

7. Huang GS, Gebb JS, Einstein MH, Shahabi S, Novetsky AP, et al. (2007)
Accuracy of preoperative endometrial sampling for the detection of high-grade endometrial tumors. Am J Obstet Gynecol 196: 243.e1-5.

8. Byrne AJ (1990) Endocyte endometrial smears in the cytodiagnosis of endometrial carcinoma. Acta Cytol 34: 373-381.

9. Suprun HZ, Taendler-Stolero R, Schwartz J, Ettinger M (1994) Experience with Endopap endometrial sampling in the cytodiagnosis of endometrial carcinoma and its precursor lesions. I. A correlative cytologic-histologic-hysteroscopic diagnostic pilot study. Acta Cytol 38: 319-323.

10. Meisels A, Jolicoeur C (1985) Criteria for the cytologic assessment of hyperplasias in endometrial samples obtained by the Endopap endometrial sampler. Acta Cytol 29: 297-302.

11. LaPolla JP, Nicosia S, McCurdy C, Songster C, Ruffolo E, et al. (1990) Experience with the EndoPap device for the cytologic detection of uterine cancer and its precursors: acomparison of the EndoPap with fractional curettage or hysterectomy. Am J Obstet Gynecol 163: 1055-1059; discussion 1059-1060.

12. Palermo VG, Blythe JG, Kaufman RH (1985) Cytologic diagnosis of endometria adenocarcinoma using the Endo-pap sampler. Obstet Gynecol 65: 271-275.

13. Van den Bosch T, Vandendael A, Wranz PA, Lombard CJ (1996) Endopapversus Pipelle- sampling in the diagnosis of postmenopausal endometrial disease. Eur J Obstet Gynecol Reprod Biol 64: 91-94.

14. Tsuda H, Kawabata M, Yamamoto K, Inoue T, Umesaki N (1997) Prospective study to compare endometrial cytology and transvaginal ultrasonography for identification of endometrial malignancies. Gynecol Oncol 65: 383-386.

15. MacKenzie IZ (1992) Endometrial biopsy. Current Obstet Gynaecol 2:162-167.

16. Stovall TG, Ling FW, Morgan PL (1991) A prospective, randomized comparison of the Pipelle endometrial sampling device with the Novak curette. Am J Obste Gynecol 165: 1287-1290.

17. Ferenczy A, Gelfand MM (1984) Outpatient endometrial sampling with Endocyte: comparative study of its effectiveness with endometrial biopsy. Obstet Gynecol 63: 295-302.

18. Oda M, Ishii Y, Omura M, Ishida N, Takeda T, et al (2000) Cytological findings of endometrial cancer. With emphasis on structural abnormalities. J Japan Soc Clin Cytol 39: 374-380. [in Japanese]

19. Ishii Y, Fujii M (1997) Criteria for differential diagnosis of complex hyperplasia or beyond in endometrial cytology. Acta Cytol 41: 1095-1102.

20. Melzack R (1975) The McGill Pain Questionnaire: major properties and scoring methods. Pain 1: 277-299.

21. Kipp BR, Medeiros F, Campion MB, Distad TJ, Peterson LM, et al. (2008) Direc uterine sampling with the Tao brush sampler using a liquid-based preparation method for the detection of endometrial cancer and atypical hyperplasia: a feasibility study. Cancer 114: 228-235.

22. Norimatsu Y, Kouda H, Kobayashi TK, Shimizu K, Yanoh K, et al. (2009) Utility of liquid-based cytology in endometrial pathology: diagnosis of endometrial carcinoma. Cytopathology 20: 395-402.

23. Kyroudi A, Paefthimiou M, Symiakaki H, Mentzelopoulou P, Voulgaris Z, et al. (2006) Increasing diagnostic accuracy with a cell block preparation from thinlayer endometrial cytology: a feasibility study. Acta Cytol 50: 63-69. 